Ciência e Natura, Santa Maria, v. 37 Part 1. 2015, p. 05-11

\title{
Effect of Temperature on thermodynamic parameters and chemical properties at adsorption process nitrite on the Graphene Nano surface, density functional theory method
}

\author{
Roya Ahmadi ${ }^{1,}$, Eysa Farajpour ${ }^{2}$ \\ 1,2 Department of Chemistry, Yadegar-e-Imam Khomeini (RAH) Branch, Islamic Azad University , \\ P.O. Box 18155-144, Tehran, Iran \\ "Corresponding Author: e-mail: roya.ahmadi.chem@hotmail.com,
}

\begin{abstract}
The project is comparing four types of calculation derived graphene. That two of these derivatives of graphene carbon nitrite connection created the difference is only in the state of Para and meta carbons connectivity state. But other derivatives first silicon-carbon alternatives in the meta and para position, then nitrite is added to the silicon. To evaluate the effect of silicon element to absorb energy and other thermodynamic parameters in the derivatives compared with them.
\end{abstract}

Keywords: nitrite, Graphene, silicon, thermodynamic parameters, Temperature 


\section{Introduction}

$\mathrm{N}$ ano Structure Graphene has a single layer. Due to the extraordinary material properties and electrical conductivity thermal conductivity, high density, optical conductivity and mechanical properties of the material has become unique. The new solid-state system by these extraordinary properties as good candidates to replace silicon in the next generation of photonic and electronic segment is considered and hence the unprecedented attention in basic and applied research has attracted. Band gap energy range is said to be occupied by electrons and is important for electronic applications. Create a band gap in graphene electron energy range an essential prerequisite for the use of graphene transistors. the project to replace silicon in place of carbon in graphene are looking at changes, the removal of nitrite as a water pollutants is of unique importance enjoys, in this research project nitrite ion absorption by the nanostructured graphene impact on the absorption of silicon element is checked. In this research nitrite ion absorption by the nanostructured graphene impact on the absorption of silicon element is checked and then by replacing silicon instead of carbon in graphene in the same position again $\mathrm{NO}_{2}$ molecules on silicon surface in two meta and paraconnected mode, Different scenarios to optimize the geometry and the calculation of the energy consumption in order to calculate thermochemistry parameters were performed on them. The thermal energy of the cases studied, enthalpy, entropy, Gibbs free energy and thermal energy in the calculation of carbon and silicon case, and were compared. In this study, density functional theory and calculation method of calculating the level B3lyp / 6-31g and in the gas phase is done.

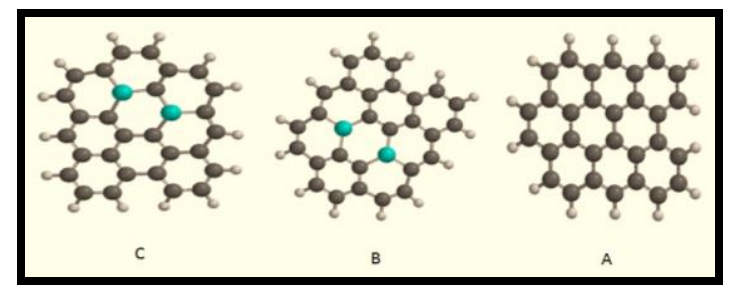

Figure 1. A: Ger B: Ger Si2 Para C: Ger Si2 Meta. Gray ball: $\mathrm{C}$ atom, Blue ball: $\mathrm{Si}$ atom

\section{Research stage}

To make the project easily be checked, fourderived graphene and abbreviations are defined separately.

A) First compound that is formed from 2 Nitrite is absorbed on the surface of Graphene (Ger) (Figure. 1) In the Para position relative to each other, with the Latin letter $\mathrm{P}$ is displayed

B) Second compound which consists of 2 Nitrite is absorbed on the surface of Graphene (Ger) (Figure. 1) In the meta position relative to each other, with the Latin letter M is displayed.

C) The third compound that consists of 2 Nitrite is absorbed on the surface of Ger $\mathrm{Si}_{2} \mathrm{P}$ (Figure. 1) In the meta position relative to each other, with the Latin letter $\mathrm{P}^{*}$ is displayed.

D) Fourth compound that consists of 2 Nitrite is absorbed on the surface of Ger $\mathrm{Si}_{2} \mathrm{M}$ (Figure. 1) In the meta position relative to each other, with the Latin letter $\mathbf{M}^{*}$ is displayed Figure 2.
M

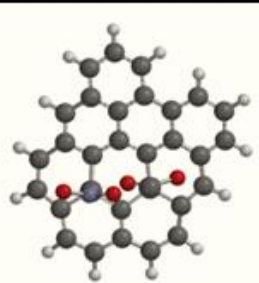

$M^{*}$

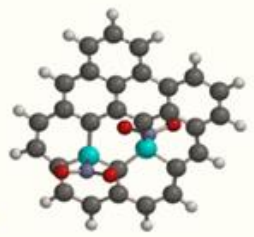

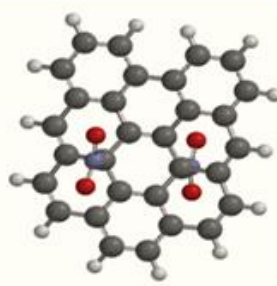

P*

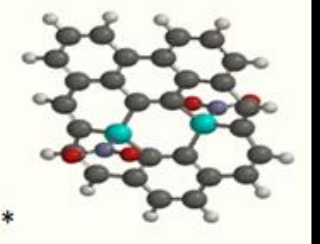

Figure 2. Derivatives investigated in this study P: Ger (NO2) 2 para, M: Ger (NO2) 2Meta, P*: Ger Si2 (NO2) 2 Para, M*: Ger Si2 (NO2) 2 Meta.

Gray ball: $\mathrm{C}$ atom, Blue ball: $\mathrm{Si}$ atom

\section{Calculation and Results:}

\subsection{Reviews the Energy Gap, Chemical potential, Chemical hardness, Electrophilicity and $\Delta$ Nмax:}


The calculations NBO, energy occupied the highest level (EHOMO) and the lowest unoccupied level (ELOMO)extract, and using mathematical equations, Chemical potential, Chemical hardness, Electrophilicity, $\Delta \mathrm{N}_{\operatorname{MAx}}$ and Energy Gap values is obtained.

The formula (1) in order to obtain chemical hardness (y)was used.

$\boldsymbol{y}=\frac{\text { E LOMO-E HOMO }}{2}$

II. Meanwhile, using the formula (2) chemical potential $(\mu)$ of the compounds were calculated.

$\mu=\frac{\text { E LOMO }+ \text { E HOMO }}{2}$

III. The formula for calculate electrophilicity:

$$
\omega=\frac{p 2}{\eta \times 2}
$$

IIII. The energy gap or distance between the level of HOMO and LUMO obtained from the following equation.

$$
\text { HLG = Eномо-ELUMo }
$$

$\mathrm{V}$. The rate of electron transfer reactions in the equation using the following equation can be obtained $\triangle \mathrm{N}$ MAX.

$$
\Delta \mathbf{N}_{\text {MAX }}=-(\boldsymbol{\mu} / \mathbf{\eta})
$$

HOMO and LUMO energy level values of the compounds tested are given in the table .1. HOMO and LUMO energy levels in Graphene in a meta-level connectivity silicon nitrite to show significant decline.

Table 1: amounts of HOMO and LOMO of derivatives investigated in this study calculated by DFT method

\begin{tabular}{|c|c|c|}
\hline Compounds & $\begin{array}{c}\mathrm{E}_{\text {LOMO }} \\
\text { (a.u) }\end{array}$ & $\begin{array}{c}\mathrm{E}_{\text {HOMO }} \\
(\mathrm{a} . \mathrm{u})\end{array}$ \\
\hline $\mathrm{P}$ & 0.139 & -0.213 \\
\hline $\mathrm{M}$ & 0.139 & -0.213 \\
\hline $\mathrm{P}^{*}$ & 0.133 & 0.224 \\
\hline $\mathrm{M}^{*}$ & 0.035 & 0.145 \\
\hline
\end{tabular}

Amounts of gap energy, chemical hardness, chemical potential, electrophilicity, dipole moment and $\triangle \mathrm{N}_{\operatorname{Max}}$ in different connection with carbon and silicon nitrite graphene surface is given in the table 2.

Table 2: compares the energy gap, chemical hardness, chemical potential, electrophilicity, dipole moment and $\triangle \mathrm{NMAX}_{\mathrm{M}}$ of derivatives investigated in this study calculated by DFT method

\begin{tabular}{|c|c|c|c|c|}
\hline Compounds & $\mathrm{P}$ & $\mathrm{M}$ & $\mathrm{P}^{*}$ & $\mathrm{M}^{*}$ \\
\hline$\Delta \mathrm{N}_{\mathrm{MAx}}$ & 0.2102 & 0.2102 & 0.5098 & 0.611 \\
\hline dipole moment & 1.0061 & 1.352 & 10.46 & 10.0522 \\
\hline electrophilicity & 0.00389 & 0.00389 & 0.02319 & 0.0168 \\
\hline chemical potential & -0.037 & -0.037 & -0.091 & -0.055 \\
\hline chemical hardness (a.u) & 0.176 & 0.176 & 0.179 & 0.09 \\
\hline gap energy (a.u) & 0.352 & 0.352 & 0.357 & 0.18 \\
\hline
\end{tabular}

\subsection{Review the amount of energy gap}

Comparing the values of the energy gap so that, Energy gap in the compound $\mathrm{P} *$ (nitrite in Para state is connected to silicon graphene surface) than the rest, then in the case of $\mathrm{P}$ (technical connection to the graphene surface crane in Para state) and $\mathrm{M}$ (connection nitrite to carbon graphene level meta state) energy Gap equal value and in the case of $M^{*}$ (nitrite in meta silicon graphene surface is connected) has the lowest energy Gap, the difference between HOMO and less LUMO and electron transfer from the HOMO to LUMO will be easier than others.

The values show the following trends:

$\mathrm{P}^{*}>(\mathrm{P}=\mathrm{M})>\mathrm{M}$ 
The values obtained from the chemical hardness, with the same amount of energy gap.

\subsection{The trend Values the chemical potential of the compounds studied:}

Compare the values of the chemical potential can be seen, Negative chemical potential is a symbol of stability, In other words, the chemical potential in $\mathrm{P}^{*}$ (nitrite in Para state is connected to silicon Graphene surface) is less than the rest, in the case of $\mathrm{M}^{*}$ (nitrite in meta attached to the Graphene surface silicon) compared to $\mathrm{P}^{*}$ value chemical potential is great. After P (technical connection to the Graphene surface crane in Para state) and $\mathrm{M}$ (nitrite connection to the Graphene surface carbon in Meta) chemical potential equal value, although the value is greater than before, as well as modes the values show the following trends:

$\mathrm{P}=\mathrm{M}>\mathrm{M}^{*}>\mathrm{P}^{*}$

\subsection{Reviews the values of the dipole} moment of the substances studied:

The amount of dipole moment in the $\mathrm{M} *(2$ nitrite ion in Meta position to one another connected to silicon graphene surface) more than $\mathrm{P} *$ (nitrite in Para state silicon graphene surface is connected). In the M (connection 2nitrite ion to carbon in the graphene surface at Meta position to one another) and case of $\mathrm{P}$ (nitrite in para position connected to Carbon of graphene surface) has a dipole moment are low. And the values indicate the following trends:

$\mathrm{M}^{*}>\mathrm{P}>\mathrm{P}^{*}>\mathrm{M}$

Study of adsorption enthalpy of binding compounds resulting nanostructure with nitrite and resulting from the replacement of silicon element in the meta and para position with nitrite. First Derivatives investigated in this study P: Ger $\left(\mathrm{NO}_{2}\right) 2$ para, M: Ger $\left(\mathrm{NO}_{2}\right)$ 2Meta, $\mathrm{P}^{*}$ : Ger Si2 $\left(\mathrm{NO}_{2}\right)_{2}$ Para, $\mathrm{M}^{*}$ : Ger Si2 $\left(\mathrm{NO}_{2}\right) 2$ Meta were optimized, in order to calculate the enthalpy of absorption, IR calculations were carried out, all calculations in the B3lyp/6-31g computational level, 298 temperature and 1 atmospheric pressure were performed. for investigating below reactions:

Ger $+2 \mathrm{NO}_{2} \rightarrow \operatorname{Ger}\left(\mathrm{NO}_{2}\right)_{2} \quad$ Meta $(\mathrm{M})$ or Para $(\mathrm{P})$

$\operatorname{GerSi} 2+2 \mathrm{NO}_{2} \rightarrow \operatorname{GerSi} 2\left(\mathrm{NO}_{2}\right)_{2} \operatorname{Meta}\left(\mathrm{M}^{*}\right) \operatorname{or} \operatorname{Para}\left(\mathrm{P}^{*}\right)$

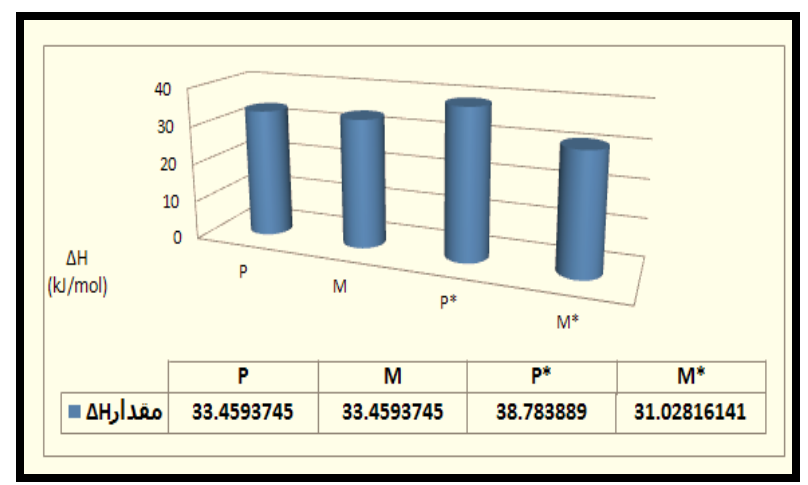

Chart table (1) compounds $\Delta \mathrm{H}$ values $\mathrm{P}, \mathrm{M}$, $\mathrm{P}^{*}$ and $\mathrm{M}^{*}$ according $\mathrm{kJ} / \mathrm{mol}$

The values of $\Delta \mathrm{H}$ indicates that the process of adsorption on Graphene reactions 5 and 6 , are the endothermic process Chart table (1).

\section{The study of thermodynamic parameters at different temperatures}

Using Spartan program, enthalpy, Entropy, heat capacity and Gibbs free energy values for Graphene (Ger), Ger $\left(\mathrm{NO}_{2}\right)_{2}$ para $(\mathrm{P})$, Ger $\left(\mathrm{NO}_{2}\right)_{2}$ Meta (M), Ger Si2 $\left(\mathrm{NO}_{2}\right)_{2}$ Para $\left(\mathrm{P}^{*}\right)$, Ger $\mathrm{Si}_{2}\left(\mathrm{NO}_{2}\right)_{2}$ Meta $\left(\mathrm{M}^{*}\right)$ In the temperature range $300-400 \mathrm{~K}$ Were calculated.

\subsection{The first results of Enthalpy changes $\left(\mathrm{H}^{\circ}\right)$ :}

To evaluate the effect of temperature on thermodynamic parameters at first the enthalpy of compounds Case Study, In the temperature range 300-400K Were calculated and compared together. In all cases studied, Enthalpy values are increased with increasing temperature (table.3). 
Table (3) Enthalpy ( $\mathrm{kJ} / \mathrm{mol})$ values of Derivatives investigated in this study, calculated by DFT method.

\begin{tabular}{|c|c|c|c|c|c|}
\hline Temperature & GER & $\mathbf{M}^{*}$ & $\mathbf{P}^{*}$ & $\mathbf{M}$ & \multicolumn{1}{|c|}{ P } \\
\hline 300 & 1067.2885 & 1033.4139 & 1033.3604 & 1149.2798 & 1149.2745 \\
\hline 310 & 1070.0561 & 1036.4249 & 1036.3759 & 1152.6715 & 1152.6665 \\
\hline 320 & 1072.9363 & 1039.5439 & 1039.5059 & 1156.1694 & 1156.1644 \\
\hline 330 & 1075.9289 & 1042.7515 & 1042.7142 & 1159.7923 & 1159.7873 \\
\hline 340 & 1079.0337 & 1046.0718 & 1046.0074 & 1163.5394 & 1163.5344 \\
\hline 350 & 1082.2449 & 1049.4658 & 1049.3899 & 1167.41 & 1167.4049 \\
\hline 360 & 1085.5318 & 1052.9134 & 1052.8193 & 1171.4031 & 1171.398 \\
\hline 370 & 1088.9048 & 1056.4441 & 1056.3105 & 1175.478 & 1175.4729 \\
\hline 380 & 1092.386 & 1060.0441 & 1059.8815 & 1179.6119 & 1179.6092 \\
\hline 390 & 1095.9287 & 1063.7217 & 1063.5575 & 1183.8051 & 1183.8029 \\
\hline 400 & 1099.5593 & 1067.4959 & 1067.3375 & 1188.1138 & 1188.1116 \\
\hline
\end{tabular}

\subsection{The second results of Entropy ( $\mathrm{S}^{\circ}$ )}

Then to evaluate the effect of temperature on entropy of compounds Case Study, In the temperature range $300-400 \mathrm{~K}$ Were calculated and compared together. In all cases studied, Entropy values are increased with increasing temperature (table.4).

Table (4) Entropy values of Derivatives investigated in this study, calculated by DFT method

\begin{tabular}{|l|l|l|l|l|l|}
\hline \multirow{2}{*}{ Temperature } & \multicolumn{5}{|c|}{ Entropy(J/mol.K) } \\
\hline 300 & \multicolumn{1}{|c|}{ GER } & \multicolumn{1}{|c|}{ M $^{*}$} & \multicolumn{1}{c|}{$\mathrm{P}^{*}$} & $\mathrm{M}$ & \multicolumn{1}{c|}{ P } \\
\hline 310 & 480.5769 & 510.3413 & 504.852 & 564.6691 & 564.653 \\
\hline 320 & 489.162 & 519.2591 & 513.7844 & 574.5534 & 574.537 \\
\hline 330 & 497.6168 & 528.2573 & 522.7969 & 584.1512 & 584.136 \\
\hline 340 & 506.1591 & 537.3293 & 531.8828 & 593.7354 & 593.72 \\
\hline 350 & 514.7822 & 546.4685 & 541.0357 & 603.406 & 603.39 \\
\hline 360 & 523.48 & 555.6688 & 550.2492 & 613.1554 & 613.14 \\
\hline 370 & 532.1467 & 564.9241 & 559.5172 & 622.9765 & 622.961 \\
\hline 380 & 540.7661 & 574.2285 & 568.8338 & 632.8195 & 632.807 \\
\hline 390 & 549.4467 & 583.5764 & 578.1932 & 642.5602 & 642.548 \\
\hline 400 & 558.1827 & 592.8071 & 587.517 & 652.3569 & 652.345 \\
\hline & 566.9685 & 602.0321 & 596.6278 & 662.2034 & 662.191 \\
\hline
\end{tabular}

\subsection{The third results of heat capacity $(\mathrm{Cv})$}

To evaluate the effect of temperature on heat capacity of compounds Case Study, In the temperature range $300-400 \mathrm{~K}$ Were calculated and compared together. In all cases studied, heat capacity values increase with increasing temperature (table.5). 
Table (5) heat capacity values of derivatives investigated in this study, calculated by DFT method

\begin{tabular}{|l|l|l|l|l|l|}
\hline & \multicolumn{5}{|c|}{ Cv(J/mol.K) } \\
\hline Temperature & GER & M & P $^{*}$ & M & P \\
\hline 300 & 289.0854 & 314.383 & 314.7937 & 376.1375 & 376.1359 \\
\hline 310 & 300.528 & 325.9641 & 326.3851 & 388.9856 & 388.9842 \\
\hline 320 & 311.9417 & 337.4878 & 337.9158 & 401.7662 & 401.7651 \\
\hline 330 & 323.3117 & 348.9412 & 349.373 & 414.4663 & 414.4653 \\
\hline 340 & 334.6241 & 360.312 & 360.7447 & 427.0731 & 427.0724 \\
\hline 350 & 345.8658 & 371.5885 & 372.0197 & 439.5751 & 439.5746 \\
\hline 360 & 357.0247 & 382.7598 & 383.1873 & 451.961 & 451.9607 \\
\hline 370 & 368.0892 & 393.8158 & 394.2377 & 464.2206 & 464.2205 \\
\hline 380 & 379.049 & 404.7472 & 405.1619 & 476.3445 & 476.3446 \\
\hline 390 & 389.8945 & 415.5455 & 415.9516 & 488.3242 & 488.3244 \\
\hline 400 & 400.617 & 426.2031 & 426.5995 & 500.1518 & 500.1522 \\
\hline
\end{tabular}

4.3 The fourth results of Gibbs free energy $\left(G^{\circ}\right)$ Then to evaluate the effect of temperature on entropy of compounds Case Study, In the temperature range 300-400K Were calculated and compared together in all cases studied, the values of Gibbs free energy $\left(G^{\circ}\right)$, are reduced with increasing temperature (table.6).

Table (6) Gibbs free energy $\left(G^{\circ}\right)$ values of derivatives investigated in this study, calculated by DFT method

\begin{tabular}{|c|c|c|c|c|c|}
\hline \multirow[b]{2}{*}{ Temperature } & \multicolumn{5}{|c|}{$\mathrm{G}^{\circ}(\mathrm{kJ} / \mathrm{mol} . \mathrm{K})$} \\
\hline & GER & $\mathbf{M}^{*}$ & $\mathbf{P}^{*}$ & $\mathbf{M}$ & $\mathbf{P}$ \\
\hline 300 & 923.1155 & 880.3115 & 881.9048 & 979.8791 & 979.8786 \\
\hline 310 & 918.4159 & 875.4546 & 877.1027 & 974.5599 & 974.5601 \\
\hline 320 & 913.6989 & 870.5015 & 872.2109 & 969.241 & 969.241 \\
\hline 330 & 908.8965 & 865.4328 & 867.1928 & 963.8596 & 963.8598 \\
\hline 340 & 904.0077 & 860.2725 & 862.0552 & 958.3814 & 958.3817 \\
\hline 350 & 899.0269 & 854.9817 & 856.8027 & 952.8056 & 952.8061 \\
\hline 360 & 893.959 & 849.5407 & 851.3931 & 947.1316 & 947.1322 \\
\hline 370 & 888.8213 & 843.9795 & 845.842 & 941.3348 & 941.3343 \\
\hline 380 & 883.5963 & 838.285 & 840.1681 & 935.439 & 935.4411 \\
\hline 390 & 878.2374 & 832.527 & 834.4259 & 929.3859 & 929.3886 \\
\hline 400 & 872.7719 & 826.6831 & 828.6864 & 923.2324 & 923.2352 \\
\hline
\end{tabular}

\section{Conclusion:}

Compare enthalpy values for different scenarios studied indicate that the mode $M^{*}$ is more likely, the state $\mathrm{P}, \mathrm{M}$ possible to achieve the same, $\mathrm{P}^{*}$ is more difficult than others states. So adsorption on surface of composite Graphenesilicon (Meta) shows better adsorption than other derivatives investigated in this study.

6 Acknowledgments 
This work was performed in Yeager-e-Imam Khomeini (RAH) (Shahre Rey) Branch Islamic Azad University so is gratefully acknowledged.

References

Ferrari, S. L. P., Cribari-Neto, F. (2004). Beta regression for modelling rates and proportions. Journal of Applied Statistics, 31(7), 799-815.

R Development Core Team (2009). R: A language and environment for statistical computing. $R$ Foundation for Statistical Computing, Vienna, Austria, URL

Mery jc, Gemim AK, Katsnelson MI, Novoselov KS, вooth TJ, Ro th S,( 2007) The Structure of
The authors also thank to Professor Jamshid Najaf pour for providing the software Spartan and for his helpful comments Suspended grapheme sheets, Nature, 446:60e3.

Balandin AA, Bhosh S, Bao W, calizo I, Teweldebrhan D, Miao F, (2008) etal. Superior thermal conductivity of single- layer grapheme, Nano left, 8:902e7.

Peigney A, Laurent C, Flahant E, Bacsa RR, Rousset A. (2007)Specific surface area of carbon nanotubes and bundles of carbon nanotubes. Carbon, 39, 507 e 14 